\title{
MECHANICAL PROPERTIES OF TENSILE AND BENDING STRENGTH ANALYSIS IN BIOCOMPOSITE [SAGOO/PMMA] MATERIAL
}

\author{
Ibnu Abdul Rosid ${ }^{1)}$, Ikbal Rizki Putra ${ }^{2)}$, Alva Edy Tontowi ${ }^{3)}$ \\ Jurusan Teknik Industri, Departemen Teknik Mesin dan Industri, Fakultas Teknik, \\ Universitas Gadjah Mada \\ Jalan Grafika No. 2, Yogyakarta 55281, Indonesia \\ Email : ${ }^{1}$ Ibnu.abdul.r@mail.ugm.ac.id
}

\begin{abstract}
Biocomposite material is a common material used in biomedical application. One of medical problems related to bone restoration which caused by accidents and injuries resulted in fracture bone parts. Biocomposite (Sagoo/PMMA) is being developed as a solution to solve that particular problem. In current research, tensile and flexural strength of sagoo/PMMA is tested and examined. There are correlation between value of tensile strength, value of bending strength, and curing time, with maximum tensile strength and bending strength were achieved by curing the specimen for 12 hours, with the maximum value of tensile strength is 3,337 MPa, and the maximum flexural is 2,653 MPa. The minimum tensile strength was achieved by curing the specimen for 6 hours with minimum value of tensile strength is 1,502 $\mathrm{MPa}$, while the minimum flexural was acquired at curing time for 24 hours with minimum of bending strength is 0,536 MPa.
\end{abstract}

Keywords: biocomposite, tensile strength, bending strength, curing time

\section{Pendahuluan}

Salah satu tantangan dalam bidang medis adalah berkaitan dengan restorasi tulang manusia yang disebabkan karena trauma atau keadaan lain yang mengakibatkan hilangnya sebagian atau keseluruhan tulang ${ }^{[1]}$, untuk menangani permasalahan tersebut dikembangkan berbagai solusi dalam ilmu rekayasa jaringan (tissue engineering), sebagai salah satu dalam bidang kajian rekayasa jaringan ${ }^{[2]}$. Komposit tersusun dari matriks dan penguat unsur utama, matriks digunakan sebagai penguat serta pelindung serat dalam komposit, matriks diperlukan untuk meneruskan beban eksternal dalam serat ${ }^{[3]}$. Material biokomposit [Sagu/PMMA] dikembangkan untuk sebaai alternatif dalam menangai permasalahan tersebut. Material biokomposit [Sagu/PMMA] menggunakan campuran perbandingan Sagu dan polymethyl methacrylate (PMMA) 1:1 dengan tambahan methyl methacrylate sebesar 50\% dari massa PMMA yang digunakan. Adapun pada material tersebut ${ }^{[2]}$ belum dilakukan uji properti mekanik, sehingga pada penelitian ini membahas mengenai uji properti mekanik material biokomposit sagu dan PMMA berupa pengujian tarik dan pengujian bending untuk mendapatkan informasi mengenai properti mekanik material biokompoist [Sagu/PMMA].

\section{Metodologi Penelitian}

Penelitian yang dilakukan merupakan penelitian eksperimental yang dilakukan di Laboratorium Bioceramic Departemen Teknik Mesin dan Industri Fakultas Teknik Universitas Gadjah Mada. Penelitian berbasiskan analisis properti mekanik material biokomposit [Sagu/PMMA] dilakukan agar mendapatkan sifat-sifat mekanik dari material atau spesimen tersebut, hal tersebut dilakukan untuk mengetahui bagaimana kemampuan mekanik dari material biokomposit [Sagu/PMMA] sehingga proyeksi penggunaan material 
dapat diperhitungkan agar perbaikan dapat dilakukan terkait properti mekanik pada material tersebut.

Proses pembuatan material biokomposit dilakukan dengan cara mencampuran material sagu dengan PMMA sebesar 1:1, kemudian ditambahkan aquades sebesar 25\% dari berat PMMA, air cuka sebesar 25\% dari berat PMMA, dan gliserin 25\% dari berat PMMA, kemudian diaduk dengan menggunakan stirrer selama 30 menit dalam suhu ruang, kemudian suhu dinaikkan sampai $50^{\circ} \mathrm{C}$ hingga campuran mengental. Setelah campuran mengental, kemudian dicampurkan MMA sebesar 50\% dari berat PMMA, lalu campuran diaduk hingga tercampur merata. Spesimen uji tarik dan bending dibuat dengan menggunakan cetakan yang sesuai dengan ASTM. Pada uji tarik menggunakan standard ASTM D628, sedangkan uji bending menggunakan ASTM D790. Spesimen kemudian berikan treatmen berupa pemanasan (curing) dalam beberapa variabel pengujian, yaitu dalam durasi 6 jam, 12 jam, dan 24 jam yang dilakukan di dalam inkubator. Kemudian dilakukan proses pengujian tarik dan bending menggunakan Universal Testing Machine (UTM) HT-2402 2000 kN yang dimiliki oleh Laboratorium Bioceramic Departemen Teknik Mesin dan Industri Universitas Gadjah Mada.

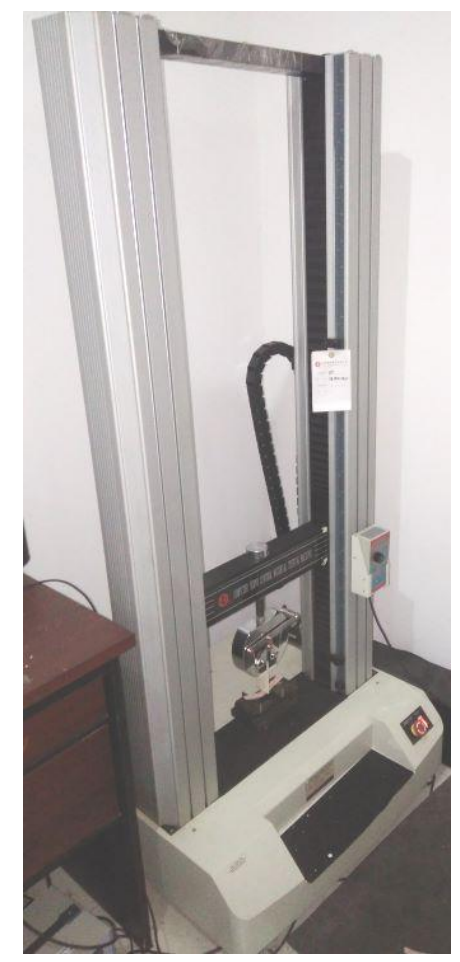

Gambar 1. Universal Testing Machine (UTM)

Proses uji kekuatan tarik dilakukan dengan cara memberikan gaya tarik pada spesimen yang dilakukan secara perlahan, hingga spesimen tersebut putus, pada pengujian tarik akan dilakukan pengukuran mengenai perpanjangan, batas mulur, kekuatan tarik, dan lain sebagainya ${ }^{[4]}$. Skema uji tarik dijelaskan pada gambar 2. 


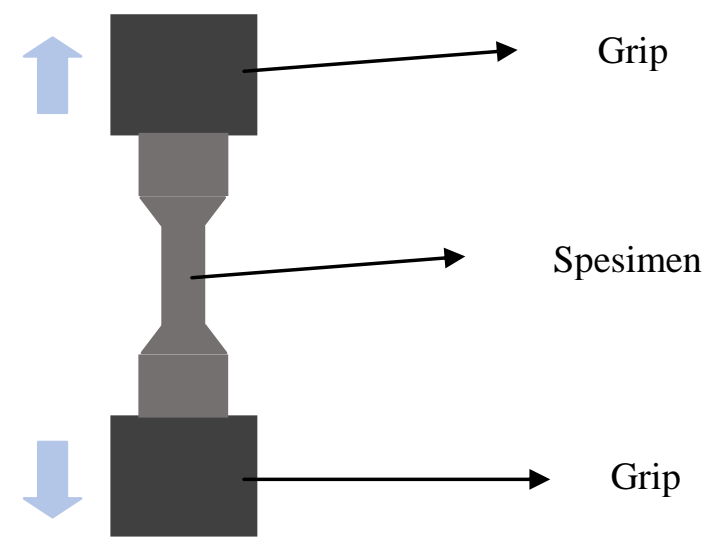

Gambar 2. Skema pengujian tarik

Kekuatan tarik diperlukan untuk melengkapi infomasi yang diperlukan dari spesimen atau material yang diuji. Berikut adalah persamaan untuk mendapatkan nilai kekuatan tarik ${ }^{[5]}$

$$
\sigma=\mathrm{P} / \mathrm{A}_{\mathrm{o}}
$$

Keterangan :

$\sigma=$ Tegangan tarik

$\mathrm{P}=$ Beban yang diberikan

$\mathrm{A}_{\mathrm{o}}=$ Luas penampang spesimen

Proses uji bending digambarkan pada gambar 3. Proses bending dilakukan pada spesimen dengan memberikan gaya pada titik tengah spesimen. Kekuatan bending maksimal pada metode three points bending [3]. Pada gambar 3 skema uji bending menggunakan metode three points bending, gaya diberikan pada sumbu tengah spesimen, dengan memberikan dua dudukan untuk menahan gaya tekan utama. Sehingga terjadi gaya tekan pada titik tengah spesimen.

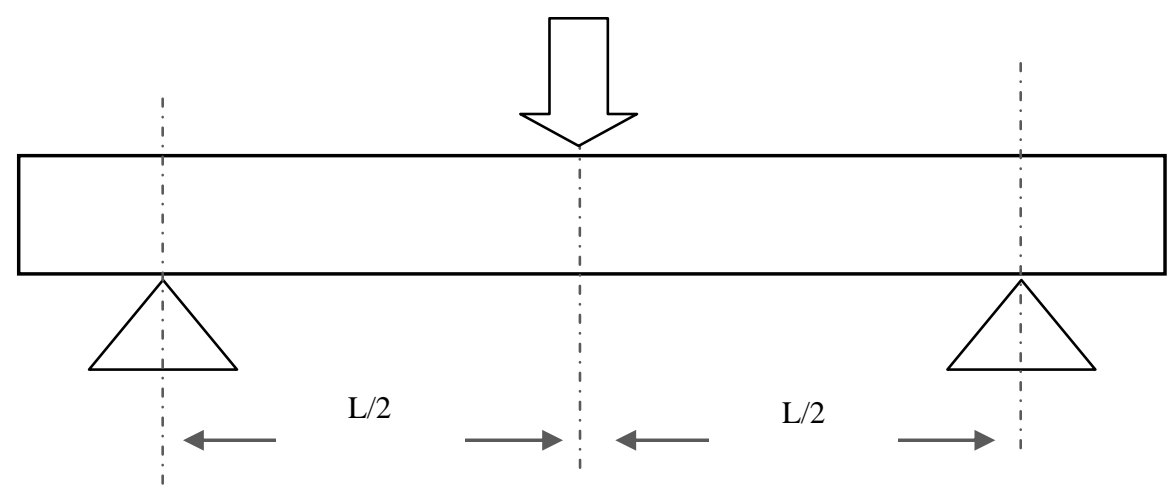

Gambar 3. Skema pengujian bending (Saduk \& Niron, 2017)

Proses uji bending digambarkan pada gambar 4, dimana proses uji tekan spesimen dilakukan dengan menggunakan mesin UTM dengan menggunakan metode three points bending. 


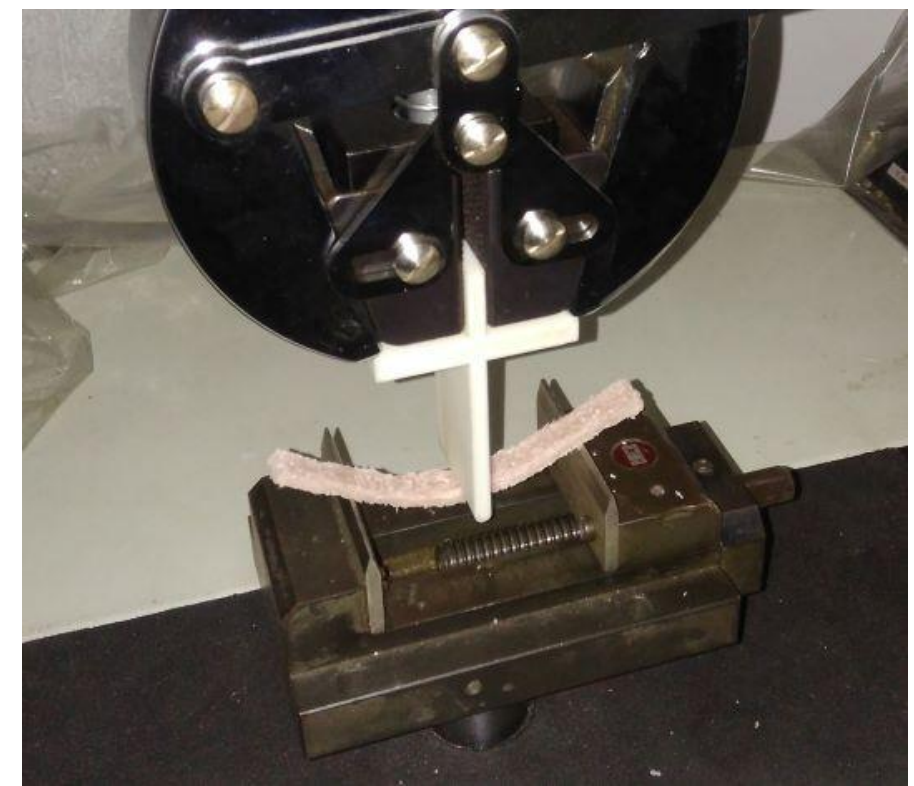

Gambar 4. Proses uji bending menggunakan mesin UTM

\section{Pembahasan}

\subsection{Uji Tarik}

Hasil pengujian kekuatan tarik material biokomposit [Sagu/PMMA] dengan perbandingan Sagu dan PMMA sebesar 1:1 dilakukan dengan menggunakan variabel waktu curing selama 6 jam, 12 jam, dan 24 jam. Hasil dari pengujian yan dilakukan didapatkan hasil kekuatan tarik seperti pada tabel 1.

Tabel 1. Hasil uji tarik

\begin{tabular}{|c|c|}
\hline Waktu Curing & Kekuatan Tarik (MPa) \\
\hline 6 Jam & 1,502 \\
\hline 12 Jam & 3,337 \\
\hline 24 Jam & 1,520 \\
\hline
\end{tabular}

Pada tabel 1 didapatkan nilai kekuatan tarik dengan waktu curing selama 6 jam, 12 jam, dan 24 jam. Pada tabel tersebut didapatkan nilai kuat tarik terbesar pada perlakuan lama waktu curing spesimen selama 12 jam, sedangkan nilai kekuatan tarik terkecil pada waktu curing selama 6 jam. Pada gambar 4 didapatkan grafik hasil uji tarik, pada grafik tersebut didapatkan kenaikan kekuatan tarik antara waktu curing 6 jam hingga 12 jam, sedangkan perlakuan waktu curing selama 24 jam mengalami penurunan kekuatan tarik spesimen. 
Mechanical Properties Of Tensile And Bending Strength Analysis In Biocomposite...

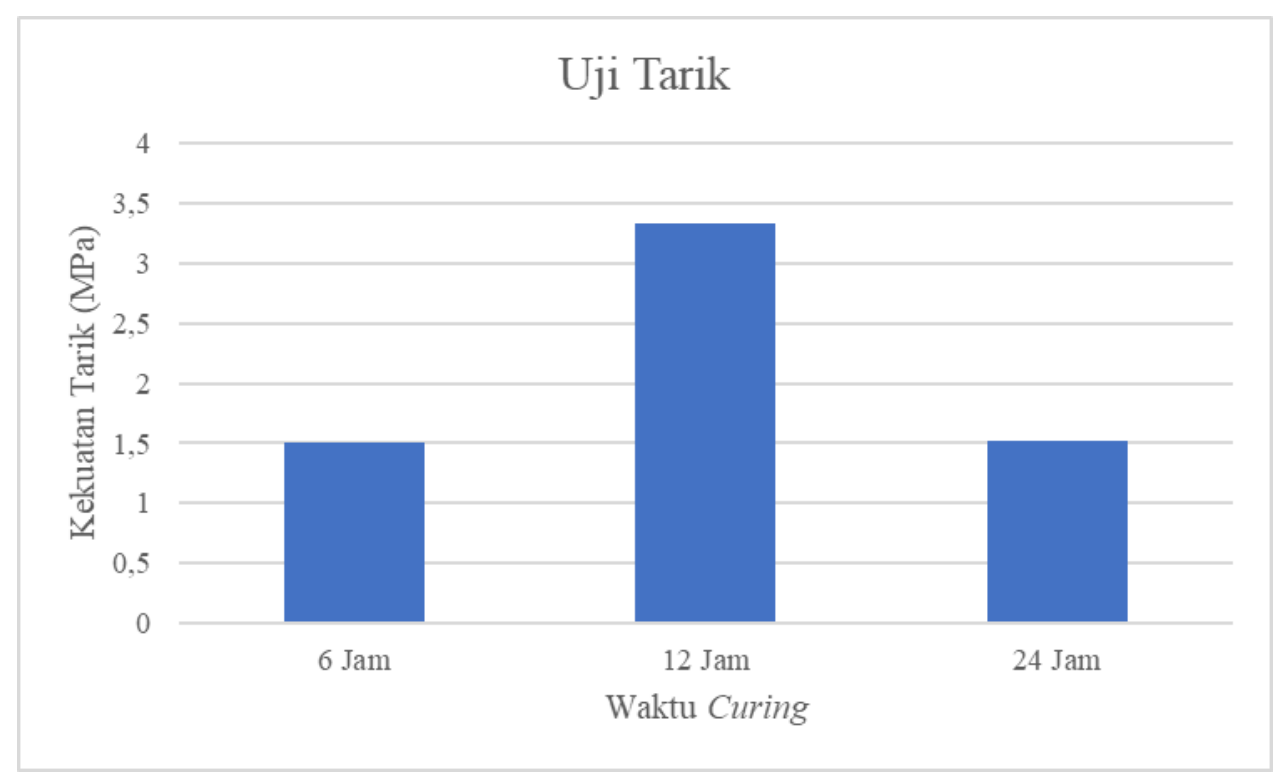

Gambar 4. Grafik hasil uji tarik

\subsection{Uji Bending}

Hasil pengujian bending material biokomposit [Sagu/PMMA] dengan perbandingan komposisi Sagu dengan PMMA sebesar 1:1 menggunakan lama waktu curing atau pemanasan selama 6 jam, 12 jam, dan 24 jam dijelaskan pada tabel 2, dimana didapatkan hasil kekuatan bending yang bervariasi.

Tabel 2 Hasil uji bending

\begin{tabular}{|c|c|}
\hline Waktu Curing & Kekuatan Bending (MPa) \\
\hline 6 Jam & 0,540 \\
\hline 12 Jam & 2,653 \\
\hline 24 Jam & 0,536 \\
\hline
\end{tabular}

Dari data pada tabel 2 didapatkan nilai kekuatan flexural tertinggi pada spesimen dengan perlakuan durasi curing selama 12 jam, sedangkan waktu curing 6 jam memiliki nilai kekuatan bending terkecil. 


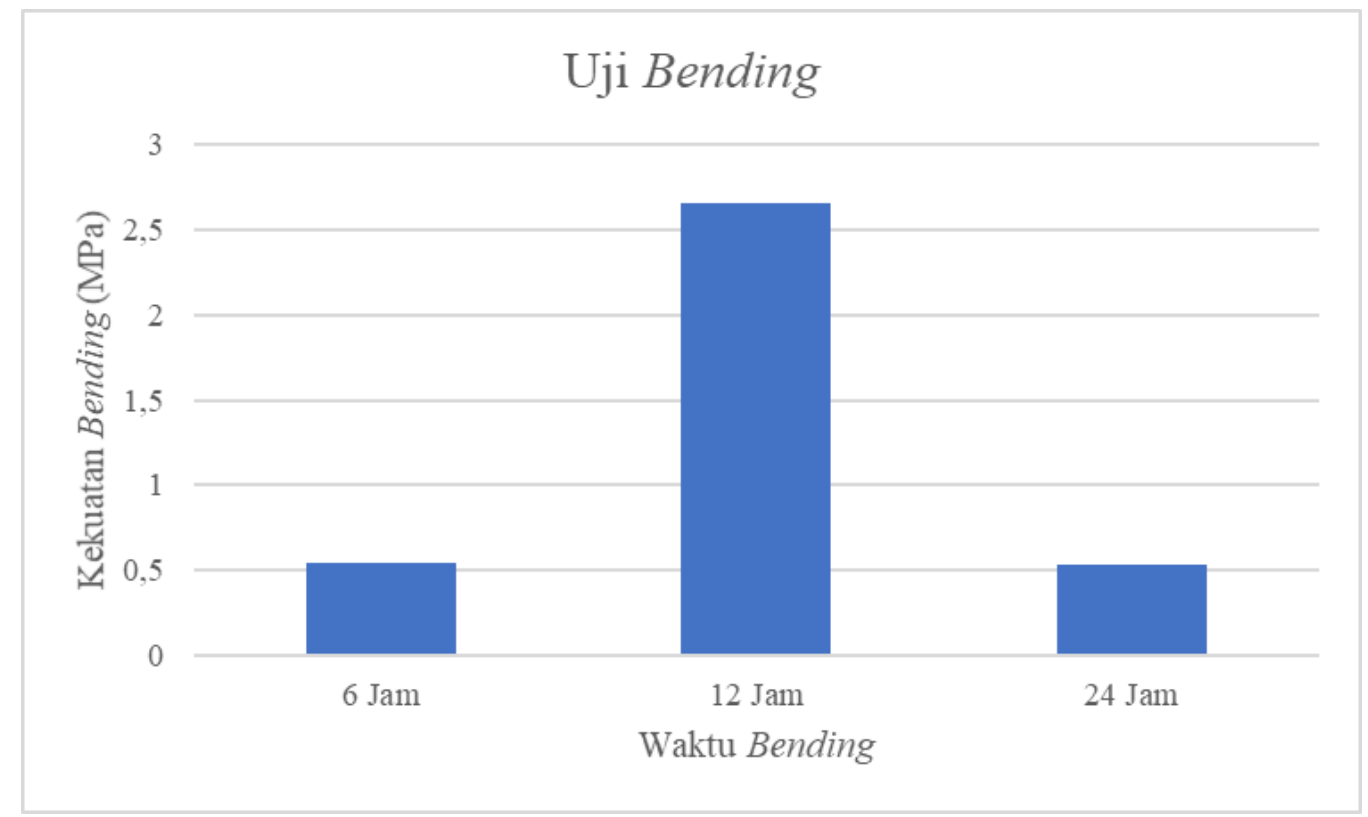

Gambar 5. Grafik hasil uji bending

Dari hasil pengujian tarik didapatkan nilai terbesar pada lama perlakuan waktu curing selama 12 jam dan memiliki nilai kekuatan tarik terkecil pada perlakuan waktu curing selama 6 jam, sedangkan pada pengujian bending didapatkan nilai kuat bending terbesar pada waktu curing selama 12 jam dan nilai bending terkecil pada waktu curing 24 jam yang dapat dijelaskan pada gambar 6 .

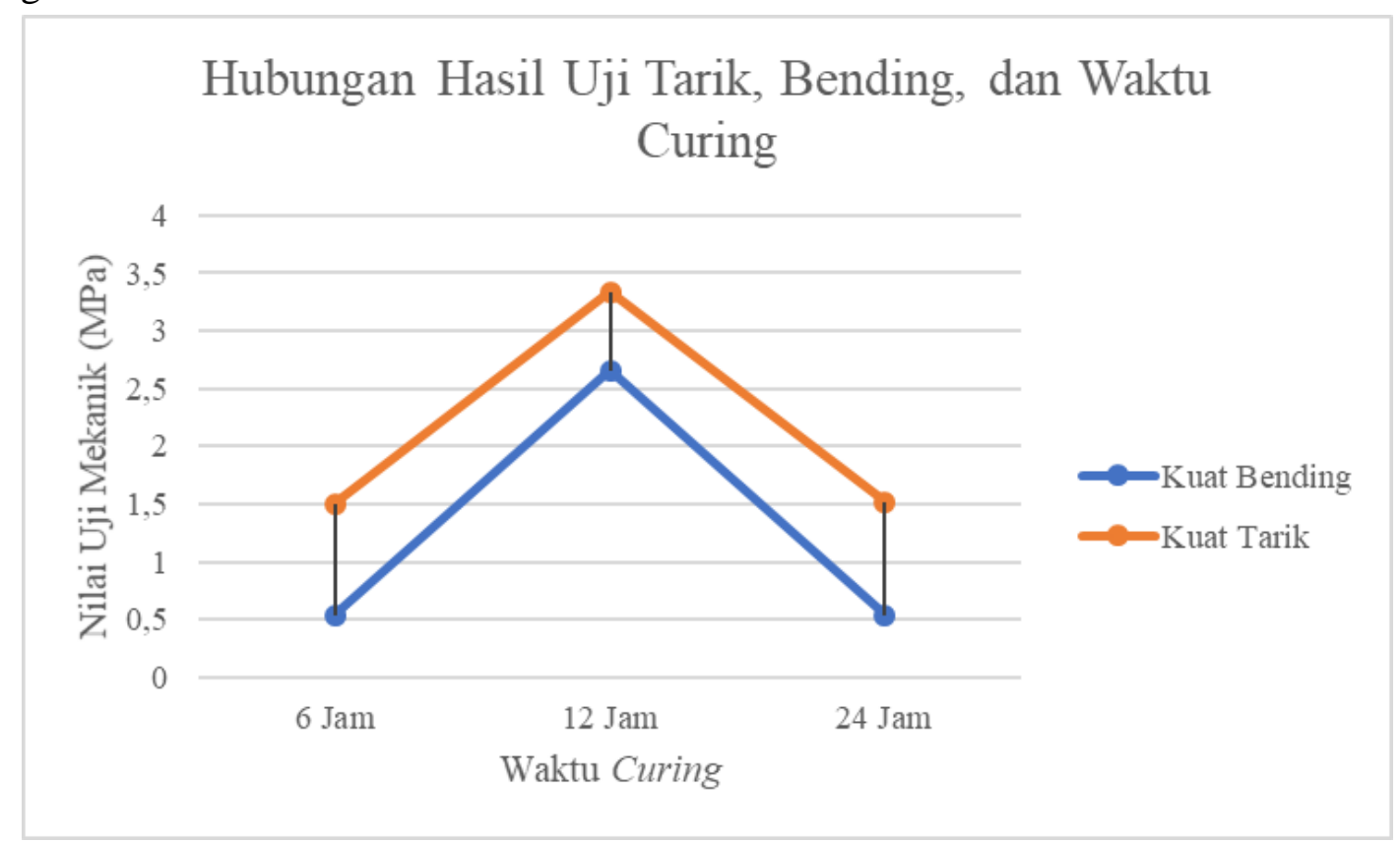

Gambar 6. Hubungan hasil uji tarik, bending, dan waktu curing

\section{Kesimpulan}

Pada penelitian mengenai pengujian properti mekanik berupa uji bending dan uji tarik material biokomposit [Sagu/PMMA] dengan waktu curing selama 6 jam, 12 jam, dan 24 jam, didapatkan kesimpulan yaitu terdapat korelasi antara perlakuan durasi pemanasan atau curing pada spesimen material biokomposit [Sagu/PMMA] terhadap kekuatan tarik dan kekuatan 
bending, yaitu hasil pengujian tarik dan bending terbesar pada waktu curing selama 12 jam dengan nilai kuat tarik terbesar sebesar 3,337 MPa dan nilai kuat bending terbesar 2,653 MPa. Sedangkan nilai kuat tarik terendah didapatkan pada perlakuan waktu curing selama 6 jam dan nilai kuat bending terendah didapatkan pada perlakuan waktu curing selama 24 jam.

\section{Ucapan Terima Kasih}

Penelitian ini didanai oleh Hibah Penelitian Departemen Teknik Mesin dan Industri Fakultas Teknik Universitas Gadjah Mada Yogyakarta 2018.

\section{Daftar Pustaka}

[1] Taufik, A., Zuhan, A., \& Kusdaryono, S. (2017). Karakterisasi hydroxyapatite alami yang dibuat dari tulang sapi dan cangkang telur sebagai bahan untuk donor tulang (bone graft). Jurnal Kedokteran UNRAM, 6(1), pp. 9-13.

[2] Putra, Ikbal Rizki \& Tontowi, Alva Edy. (2019, Februari). Properti Mekanik Material [Sagu/PMMA] “3D-Printabel”. In Conference SENIATI 2019, pp. 320-323

[3] Widhiarta, I Gede, Sari, Nasmi Herlina, \& Sujita, (2012). Study Kekuatan Bending Dan Struktur Mikro Komposit Polyethylene Yang Diperkuat Oleh Hybrid Serat Sisal Dan Karung Goni. Dinamika Teknik Mesin, 2(2), pp. 92-99.

[4] Kurniawan, Ary Setya, \& Solichin, Puspitasari, Rr. Poppy. (2014). Analisis Kekuatan Tarik Dan Struktur Mikro Pada Baja St.41 Akibat Perbedaan Ayunan Elektroda Pengelasan SMAW. Jurnal Teknik Mesin, 22(2), pp. 1-12.

[5] Lesmanah, Unung, Masyahyo, Eko, \& Vitasari, Prima. (2013). Optimasi Sifat Mekanis Kekuatan Tarik Baja St 50 Dengan Perlakuan Gas Carburizing Variasi Holding Time Untuk Peningkatan Mutu Baja Standar Uji Astm A370. Jurnal Mekanikal, 4(2), pp. 366375.

[6] Saduk, Mesiani \& Niron, Fransisko Piri. (2017). Analisis Kekuatan Bending Dan Kekuatan Impact Komposit Epoxy Diperkuat Serat Pelepah Lontar. Jurnal Rekayasa Mesin, 8(3), pp. 121-127. 
Ibnu Abdul Rosid, Ikbal Rizki Putra, Alva Edy Tontowi 